\title{
ANALISIS FAKTOR-FAKTOR YANG BERPENGARUH TERHADAP SIKAP DAN PERILAKU MEMBELI BUKU BAJAKAN PADA MAHASISWA IPB
}

\author{
An Analysis of Factors Influencing IPB Students Attitudes and Buying Behaviour of \\ Piracy Book
}

\author{
RETNANINGSIH ${ }^{1}$, PUSPA WIDYA UTAMI ${ }^{2}$, ISTIQLALIYAH MUFLIKHATI ${ }^{1^{*}}$ \\ ${ }^{1}$ Staf Pengajar Departemen IImu Keluarga dan Konsumen, Fakultas Ekologi Manusia, \\ Institut Pertanian Bogor, Jalan Lingkar Kampus IPB Dramaga, \\ Bogor 16680 \\ ${ }^{2}$ Departemen IImu Keluarga dan Konsumen, Fakultas Ekologi Manusia, Institut Pertanian \\ Bogor, Kampus Dramaga, Bogor 16680
}

\begin{abstract}
The aim of this research was to analyze factors which influence IPB students attitudes and buying behaviour of piracy book. Research method used cross sectional study design. The primary data from samples was collected along Mei 2009. Data was taken from 100 girls and 100 boys as samples of this research. The samples chosen by proportional sampling in each faculty of IPB. The data consist of primary data and secondary data. Data was analyzed by descriptive and inferential statistic (Mann-Whitney, t-test, multivariate regression, and logistic regression). The result showed that almost samples readed books and mostly they bought a book on the last three months. Almost of them had knowledge about piracy book with average level. Meanwhile, the attitude of the samples to piracy book were neutral. Factors that influenced attitude to piracy book were ages, money allocation, information resources, and level of knowledge. Then, attitude to piracy book was the factor that influenced buying behavior of piracy book.
\end{abstract}

Key words: attitude, book, consumer behavior, knowledge, piracy

\section{PENDAHULUAN}

Hak cipta merupakan bagian yang terbesar dari Hak Kekayaan Intelektual (HAKI). Sebagai negara hukum, HAKI merupakan salah satu hak yang dilindungi undang-undang di Indonesia. Ironisnya, acapkali Hak Atas Kekayaan Intelektual ini dilanggar. Pelanggaran hak cipta yang kerap terjadi di Indonesia antara lain adalah pembajakan buku. Omset penjualan buku bajakan diperkirakan mencapai $10 \%$ dari omset penjualan buku asli. Buku yang paling banyak dibajak adalah jenis kamus (20\%) dan buku teks perguruan tinggi (10\%) (Anonim 2008). Salah satu tempat pemasaran buku bajakan yang menguntungkan pembajak buku adalah perguruan tinggi. Perguruan tinggi merupakan institusi pendidikan yang menjadi pasar yang prospektif bagi pemasaran buku. Dosen dan mahasiswa merupakan konsumen utama dari penjualan buku di perguruan tinggi. Penerapan sistem mayor minor di IPB, mendorong mahasiswa untuk memiliki wawasan lebih luas dan tidak terkotak-kotak. Keadaan tersebut menuntut mahasiswa untuk lebih aktif dalam memperoleh informasi dan ilmu. Kebutuhan untuk mendukung proses pembelajaran dan meningkatkan pengetahuan, mendorong mahasiswa untuk bisa mempunyai salah satu sumber pengetahuan, yaitu buku. Diduga harga buku yang mahal atau sulit ditemukannya buku yang asli karena peredarannya terbatas atau tidak diterbitkan lagi mendorong munculnya peluang pasar untuk buku bajakan. Pasar buku bajakan terbuka lebar, salah satunya karena penjual buku bajakan yang menawarkan buku relatif lebih murah dan bisa dilakukan pemesanan sebelumnya jika tidak tersedia.

Tujuan umum dari penelitian ini adalah untuk menganalisis faktor-faktor yang 
berpengaruh terhadap sikap dan perilaku membeli buku bajakan pada mahasiswa IPB. Tujuan khusus yang ingin dicapai adalah (1) menganalisis kebiasaan mahasiswa dalam membaca dan membeli buku, (2) menganalisis pengetahuan mahasiswa terhadap buku bajakan, (3) menganalisis sikap mahasiswa terhadap buku bajakan, (4) menganalisis perilaku pembelian buku bajakan oleh mahasiswa, (5) menganalisis faktor-faktor yang berpengaruh terhadap sikap mahasiswa mengenai buku bajakan, dan (6) menganalisis faktor-faktor yang berpengaruh terhadap perilaku mahasiswa dalam membeli buku bajakan.

\section{METODE}

\section{Desain, Lokasi, dan Waktu}

Penelitian ini menggunakan disain cross sectional study. Penelitian dilakukan di Institut Pertanian Bogor (IPB) yang berlokasi di Kecamatan Dramaga, Kabupaten Bogor. Pemilihan lokasi penelitian dilakukan secara purposive (sengaja) berdasarkan pertimbangan bahwa IPB merupakan salah satu perguruan tinggi besar di Indonesia yang mahasiswanya banyak menggunakan media cetak seperti buku sebagai salah satu sumber informasi yang menunjang kegiatan perkuliahan dan tempat yang mudah ditempuh oleh Peneliti. Waktu pengambilan data dilakukan selama bulan Mei 2009.

\section{Jumlah dan Cara Pemilihan Contoh}

Populasi penelitian ini adalah mahasiswa mayor minor IPB tahun ajaran 2008-2009 yang berjumlah 11.615 orang. Berdasarkan perhitungan jumlah minimal contoh yang ditentukan dengan rumus Slovin (Umar 2003), yang dalam kasus penelitian ini diperoleh jumlah 155 orang. Untuk menghindari adanya drop out contoh atau pun kekurangan jumlah contoh, maka contoh penelitian ini diambil sebanyak 200 mahasiswa dengan komposisi berimbang antara laki-laki dan perempuan. Banyaknya jumlah contoh setiap fakultas diberikan kuota sesuai dengan proportional sampling. Proses pemilihan contoh adalah secara convinience sampling, yakni contoh dipilih berdasarkan kesediaannya untuk mengisi kuesioner dan wawancara langsung sesuai dengan kuota per fakultas.

\section{Jenis dan Cara Pengumpulan Data}

Jenis data yang digunakan berdasarkan sumber adalah data primer dan data sekunder. Data primer diperoleh secara langsung dari contoh, yakni berupa kuesioner. Data sekunder diperoleh dari buku Panduan Program Sarjana tahun 2006 mengenai gambaran umum lokasi penelitian dan data mengenai jumlah mahasiswa dari Direktorat Administrasi Pendidikan IPB. Informasi mengenai penjualan buku juga diperoleh dengan cara mewawancarai beberapa pedagang buku di sekitar kampus.

\section{Pengolahan dan Analisis Data}

Pengolahan data menggunakan Microsoft Excel dan SPSS for windows. Data yang dikumpul dari kuesioner diolah melalui proses editing, coding, scoring, entry data ke komputer, cleaning data, dan analisis data. Jenis-jenis analisis data dalam penelitian ini adalah sebagai berikut:

1. Deskriptif digunakan untuk menggambarkan karakteristik contoh, karakteristik keluarga, kebiasaan membaca, perilaku membeli buku, sikap, dan perilaku membeli buku bajakan.

2. Uji Regresi Linier Berganda metode backward digunakan untuk memprediksi perilaku dari variabel dependen dengan menggunakan lebih dari dua variabel independen. Peneliti ingin mengetahui faktor-faktor yang mempengaruhi sikap buku bajakan. Bentuk umum dari persamaan regresi linear berganda untuk persepsi sebagai berikut:

\footnotetext{
$Y=a+b_{1} X_{1}+b_{2} X_{2}+b_{3} X_{3}+b_{4} X_{4}+b_{5} X_{5}+b_{6} X_{6}+b_{7} X_{7}+$ $b_{8} X_{8}+b_{9} X_{9}+b_{10} x_{10}+b_{11} x_{11}+b_{12} X_{12}+b_{13} x_{13}+b_{14} D_{1}$
}

Keterangan:

$\mathrm{Y}=$ sikap terhadap buku bajakan

$a=$ unstandardrized coefficient $\beta$

$\mathrm{b}=$ konstanta

$\mathrm{X}_{1}=$ Usia (tahun)

$\mathrm{X}_{2}=$ Semester

$\mathrm{X}_{3}=$ Besar keluarga (org)

$\mathrm{X}_{4}=$ Pendapatan orangtua $(\mathrm{Rp})$

$\mathrm{X}_{5}=$ Frekuensi membaca

$\mathrm{X}_{6}=$ Frekuensi membeli buku

$\mathrm{X}_{7}=$ Alokasi uang membeli buku (Rp)

$\mathrm{X}_{8}=$ Jumlah sumber informasi

$\mathrm{X}_{9}=$ Pengetahuan

$\mathrm{X}_{10}=$ Pendidikan Ibu

$\mathrm{X}_{11}=$ Jumlah organisasi

$\mathrm{X}_{12}=$ Pendidikan ayah

$\mathrm{X}_{13}=$ Pendidikan ibu

$\mathrm{D}_{1}=$ Control belief $(0=$ tidak, $1=y a)$

3. Uji Regresi Logistik metode entered digunakan untuk menganalisis faktor- 
faktor yang mempengaruhi perilaku pembelian buku bajakan yang terdiri dari dua kategori yaitu membeli dan tidak membeli. Persamaan regresi logistik dirumuskan dalam persamaan:

$\frac{P}{1-P}=\mathbf{e}^{a+b 1 \times 1+b 2 \times 2+b 3 \times 3+b 4 \times 4+b 5 \times 5+}$

Keterangan:

$\mathrm{p}=$ Peluang perilaku membeli buku bajakan

( $0=$ tidak membeli, $1=$ membeli)

$a=$ unstandardrized coefficient $\beta$

$\mathrm{b}=$ konstanta

$\mathrm{X}_{1}=$ Usia

$\mathrm{X}_{2}=\mathrm{IPK}$

$\mathrm{X}_{3}=$ Uang saku $(\mathrm{Rp})$

$\mathrm{X}_{4}=$ Besar keluarga (org)

$\mathrm{X}_{5}=$ Pendapatan orangtua $(\mathrm{Rp})$

$\mathrm{X}_{6}=$ Jumlah sumber informasi

$\mathrm{X}_{7}=$ Pengetahuan

$X_{8}=$ Sikap

$\mathrm{X}_{9}=$ Alokasi uang membeli buku (Rp)

\section{HASIL DAN PEMBAHASAN}

\section{Karakteristik Contoh}

Menurut Hurlock (1980), mahasiswa termasuk usia yang memasuki kriteria remaja akhir dan masa dewasa awal. Hasil penelitian menunjukkan usia contoh antara 17 tahun hingga 23 tahun. Sebagian besar contoh berada pada masa usia dewasa awal. Agama contoh mayoritas adalah Islam, hal ini diperkirakan karena Indonesia merupakan negara dengan jumlah muslim yang sangat besar. Agama dapat dijadikan batasan konsumen dalam berperilaku, misalnya halal atau haram suatu produk atau jasa tersebut. Contoh pada penelitian ini menyatakan bahwa hampir dari seluruh contoh mendapatkan uang saku yang bersumber dari orangtua. Sebaran uang saku per bulan contoh antara Rp 100.000,00 hingga Rp 2.400.000,00.

\section{Karakteristik Keluarga Contoh}

Menurut BKKBN (1998), keluarga contoh dapat dibagi menjadi tiga kelompok, yaitu keluarga kecil, sedang, dan besar (Tabel 2). Pada penelitian ini jumlah anggota keluarga berkisar antara 2-12 orang. Lebih dari separuh contoh merupakan keluarga sedang. Pendidikan orangtua mampu mempengaruhi nilai-nilai yang dianut, cara berfikir, cara pandang, mendidik, dan mengasuh anaknya mengenai suatu masalah. Pendidikan terakhir orangtua terbanyak adalah tamat Akademi/Perguruan Tinggi/sederajat.

Tabel 1. Sebaran contoh berdasarkan karakteristik individu

\begin{tabular}{|c|c|c|}
\hline \multirow{2}{*}{ Keterangan } & \multicolumn{2}{|c|}{ Jumlah } \\
\hline & $n$ & $\%$ \\
\hline \multicolumn{3}{|l|}{ Usia } \\
\hline Remaja Akhir & 26 & 13,0 \\
\hline Dewasa Awal & 174 & 87,0 \\
\hline Total & 200 & 100,0 \\
\hline \multicolumn{3}{|l|}{ Agama } \\
\hline Islam & 190 & 95,0 \\
\hline Kristen & 9 & 4,5 \\
\hline Hindu & 1 & 0,5 \\
\hline Total & 200 & 100,0 \\
\hline \multicolumn{3}{|l|}{ Semester } \\
\hline 2 & 42 & 21,0 \\
\hline 4 & 48 & 24,0 \\
\hline 6 & 54 & 27,0 \\
\hline 8 & 56 & 28,0 \\
\hline Total & 200 & 100,0 \\
\hline \multicolumn{3}{|l|}{ Jalur masuk IPB } \\
\hline USMI & 132 & 66,0 \\
\hline SPMB & 54 & 27,0 \\
\hline BUD & 14 & 7,0 \\
\hline Total & 200 & 100,0 \\
\hline \multicolumn{3}{|l|}{ IPK } \\
\hline Rendah $(0,00-2,00)$ & 3 & 1,5 \\
\hline Sedang $(2,01-2,75)$ & 64 & 32,0 \\
\hline Tinggi $(>2,75)$ & 133 & 66,5 \\
\hline Total & 200 & 100,0 \\
\hline \multicolumn{3}{|l|}{ Uang saku } \\
\hline Kecil (Rp.0-Rp 500.000) & 38 & 19,0 \\
\hline $\begin{array}{l}\text { Sedang } \\
\text { (Rp } 500.000 \text { - Rp } 1.000 .000)\end{array}$ & 150 & 75,0 \\
\hline Besar (>Rp 1.000.000) & 12 & 6,0 \\
\hline Total & 200 & 100,0 \\
\hline
\end{tabular}

Sumarwan (2002) menyebutkan bahwa pendidikan akan menentukan jenis pekerjaan yang dilakukan konsumen. Hampir sebagian besar pekerjaan ayah merupakan Pegawai Negeri Sipil (41,7\%). Lebih dari separuh ibu contoh adalah Ibu Rumah Tangga atau tidak bekerja $(52,5 \%)$. Ibu yang tidak bekerja lebih memfokuskan diri terhadap keluarga dan pengurusan rumah tangga di bidang domestik. Sumarwan (2002) menjelaskan bahwa pendapatan merupakan imbalan yang diterima oleh seseorang dari pekerjaan yang dilakukannya untuk mencari nafkah yang biasanya dalam bentuk uang. Pendapatan orangtua berkisar antara $\mathrm{Rp} 0,00$ hingga mencapai Rp 10.000.000,00. Proporsi terbesar $(34 \%)$ pendapatan orangtua contoh adalah masuk kategori rendah (antara Rp 1.000.000,00 sampai Rp 2.000.000,00). Tidak ada perbedaan yang signifikan karakteristik keluarga contoh laki-laki dan perempuan. 
Tabel 2. Sebaran contoh berdasarkan karakteristik keluarga

\begin{tabular}{|c|c|c|}
\hline \multirow{2}{*}{ Keterangan } & \multicolumn{2}{|c|}{ Jumlah } \\
\hline & $\mathbf{n}$ & $\%$ \\
\hline \multicolumn{3}{|l|}{ Besar Keluarga } \\
\hline Kecil ( $\leq 4$ orang) & 66 & 33,0 \\
\hline Sedang (5-7 orang) & 112 & 56,0 \\
\hline Besar ( $>7$ orang) & 22 & 11,0 \\
\hline Total & 200 & 100,0 \\
\hline \multicolumn{3}{|l|}{ Pendidikan terakhir ayah } \\
\hline Tidak Sekolah & 8 & 4,0 \\
\hline Tamat SD/Sederajat & 24 & 12,0 \\
\hline Tamat SMP/Sederajat & 4 & 2,0 \\
\hline Tamat SMA/Sederajat & 62 & 31,0 \\
\hline Tamat Akedemi/PT/ Sederajat & 102 & 51,0 \\
\hline Total & 200 & 100,0 \\
\hline \multicolumn{3}{|l|}{ Pendidikan terakhir ibu } \\
\hline Tidak Sekolah & 10 & 5,1 \\
\hline Tamat SD/Sederajat & 26 & 13,1 \\
\hline Tamat SMP/Sederajat & 22 & 11,1 \\
\hline Tamat SMA/Sederajat & 66 & 33,3 \\
\hline Tamat Akademi/PT/ Sederajat & 74 & 37,4 \\
\hline Total & 198 & 100,0 \\
\hline \multicolumn{3}{|l|}{ Pekerjaan ayah } \\
\hline Tidak Bekerja & 10 & 5,2 \\
\hline Pegawai Swasta & 24 & 12,5 \\
\hline Wiraswasta & 42 & 21,9 \\
\hline Petani & 11 & 5,7 \\
\hline PNS & 80 & 41,7 \\
\hline Pensiun & 15 & 7,8 \\
\hline Lain-Lain & 10 & 5,2 \\
\hline Total & 192 & 100,0 \\
\hline \multicolumn{3}{|l|}{ Pekerjaan ibu } \\
\hline Tidak Bekerja/IRT & 103 & 52,6 \\
\hline Pegawai Swasta & 11 & 5,6 \\
\hline Wiraswasta & 21 & 10,7 \\
\hline Petani & 3 & 1,5 \\
\hline PNS & 56 & 28,6 \\
\hline Pensiun & 2 & 1,0 \\
\hline Total & 196 & 100,0 \\
\hline \multicolumn{3}{|l|}{ Pendapatan orangtua } \\
\hline Sangat rendah (<Rp 1 juta) & 38 & 19,0 \\
\hline Rendah (Rp 1-2 juta) & 68 & 34,0 \\
\hline Sedang (Rp 2-3 juta) & 37 & 18,5 \\
\hline Tinggi (Rp 3-4 juta) & 27 & 13,5 \\
\hline Sangat tinggi (> Rp 4 juta) & 30 & 15,0 \\
\hline Total & 200 & 100,0 \\
\hline
\end{tabular}

\section{Kebiasaan Membaca}

Perilaku membaca adalah tindakan yang langsung terlibat dalam kegiatan membaca meliputi pemilihan jenis bacaan yang dibaca, jumlah buku dan sejenisnya yang dibaca, dan frekuensi membaca (Akbar 2008). Hampir seluruh (95,5\%) contoh membaca buku dalam tiga bulan terakhir. Buku yang dibaca terdiri dari berbagai macam jenis, seperti buku teks/penunjang kuliah, novel, motivasi, sejarah, komik, dan lainnya.
Frekuensi membaca buku setiap orang berbeda-beda, tergantung pada minat, kemampuan, dan kebiasaan contoh untuk membaca buku. Tabel 3 menunjukkan bahwa sekitar $33,5 \%$ contoh menyebutkan bahwa mereka membaca buku dalam waktu dua hingga tiga hari sekali. Setiap orang memiliki waktu khusus untuk membaca buku agar nyaman. Lebih dari separuh contoh merasa nyaman membaca buku ketika mengisi waktu luang. Hasil tersebut serupa dengan penelitian Astiwi (2007), bahwa waktu yang nyaman bagi contoh untuk membaca majalah remaja adalah $82,6 \%$ pada waktu yang tidak tentu.

Tabel 3. Sebaran contoh berdasarkan kebiasaan membaca buku

\begin{tabular}{lrr}
\hline \multirow{2}{*}{ Keterangan } & \multicolumn{2}{c}{ Jumlah } \\
\cline { 2 - 3 } & $\mathbf{n}$ & $\%$ \\
\hline Frekuensi membaca buku & 47 & 24,6 \\
Setiap hari & 64 & 33,5 \\
2-3 hari sekali & 47 & 24,6 \\
Satu minggu sekali & 23 & 12,0 \\
Tidak tentu & 10 & 5,2 \\
Lain-lain & 191 & 100,0 \\
\hline Total & 32 & 16,0 \\
\hline Waktu yang nyaman membaca buku & \\
Pagi hari & 12 & 6,0 \\
Sore hari & 70 & 35,0 \\
Malam hari & 126 & 63,0 \\
Tidak tentu & 2 & 1,0 \\
Lain-Lain & \multicolumn{2}{c}{}
\end{tabular}

\section{Perilaku Membeli Buku}

Kebutuhan seseorang untuk memiliki suatu produk akan mendorong konsumen untuk membeli produk tersebut. Lebih dari separuh contoh (59\%) menyatakan bahwa mereka membeli buku dalam tiga bulan terakhir. Hampir seluruh contoh tidak menentukan waktu yang rutin untuk membeli buku. Alasan yang contoh kemukakan adalah aksidental. Tempat yang strategis dan mudah dijangkau dapat mempengaruhi keputusan konsumen untuk membeli suatu produk. Sebagian besar contoh (75,4\%) membeli buku di toko buku. Alokasi uang contoh umtuk membeli buku dalam tiga bulan terakhir berkisar antara Rp 0 sampai dengan Rp 300.000,00. Sebagian besar contoh $(63,6 \%)$ dalam mengalokasikan uang untuk membeli buku termasuk dalam kategori sedang (antara $\mathrm{Rp} \quad 50.000,00$ sampai dengan $R p 100.000,00)$. 
Tabel 4. Sebaran contoh berdasarkan perilaku membeli buku

\begin{tabular}{lrr}
\hline \multicolumn{1}{c}{ Keterangan } & \multicolumn{2}{c}{ Jumlah } \\
\cline { 2 - 3 } & $\mathbf{n}$ & \multicolumn{1}{c}{$\%$} \\
\hline Frekuensi Membeli Buku & 1 & 0,8 \\
Seminggu sekali & 20 & 16,9 \\
Sebulan sekali & 97 & 82,2 \\
Tidak tentu (>1 bulan) & 118 & 100,0 \\
\hline Total & & \\
\hline Tempat Membeli Buku & 89 & 75,4 \\
Toko buku & 22 & 18,6 \\
Kios buku & 24 & 20,3 \\
Pedagang kaki lima & 19 & 16,1 \\
Lain-lain & 17 & 14,4 \\
\hline Alokasi uang untuk membeli buku & \\
Tidak Menganggarkan & 17 & 14,4 \\
Rendah (< Rp 50.000) & 75 & 63,6 \\
Sedang (Rp 50.000-100.000) & 9 & 7,6 \\
Tinggi (> Rp 100.000) & 118 & 100,0 \\
\hline Total & \multicolumn{2}{c}{}
\end{tabular}

\section{Pengetahuan dan Sikap Terhadap Buku Bajakan}

Pengetahuan merupakan informasi yang disimpan dalam bentuk ingatan yang menjadi penentu utama perilaku konsumen (Engel et al. 1994). Hampir dari separuh contoh (48,5\%) memiliki pengetahuan dengan kriteria sedang. Perbedaan tingkat pengetahuan contoh dapat digunakan untuk menterjemahkan informasi baru dan membuat pilihan pembelian yang berbeda pula.

Sikap adalah gambaran perasaan dari seorang konsumen, dan perasaan tersebut akan direfleksikan oleh perilakunya (Schiffman \& Kanuk 1994). Tabel 5 menunjukkan sebagian besar $(80,5 \%)$ contoh memiliki sikap netral terhadap buku bajakan.

Tabel 5. Sebaran contoh berdasarkan tingkat pengetahuan dan sikap terhadap buku bajakan

\begin{tabular}{lrr}
\hline \multirow{2}{*}{\multicolumn{1}{c}{ Keterangan }} & \multicolumn{2}{c}{ Jumlah } \\
\cline { 2 - 3 } & \multicolumn{1}{c}{$\mathbf{n}$} & \multicolumn{1}{c}{$\%$} \\
\hline Pengetahuan & & \\
Rendah & 73 & 36,5 \\
Sedang & 97 & 48,5 \\
Tinggi & 30 & 15,0 \\
\hline Total & 200 & 100,0 \\
\hline Sikap & & \\
Negatif & 24 & 12,0 \\
Netral & 161 & 80,5 \\
Positif & 15 & 7,5 \\
\hline Total & 200 & 100,0 \\
\hline
\end{tabular}

Menurut Sumarwan (2002) sikap netral adalah salah satu karakteristik valance dari sikap, yakni tiga dimensi sikap positif, netral dan negatif. Diduga pada kategori netral ini contoh memiliki tingkat kecenderungan resisten yang mudah berubah ke arah sikap positif atau negatif. Perubahan tersebut dapat dipengaruhi oleh keyakinan sikap, konsistensi sikap, pengetahuan, perasaan, dan situasi (Sumarwan 2002).

\section{Perilaku Membeli Buku Bajakan}

Pembelian dipengaruhi pengenalan kebutuhan yang terdiri dari berbagai faktor baik individu, lingkungan atau situasi. Sebagian besar contoh membeli buku bajakan $(75,0 \%)$ pada satu tahun terakhir. Besar uang yang dianggarkan contoh untuk membeli buku bajakan antara Rp 0 hingga Rp 500.000,00, dan hampir separuh contoh $(47,3 \%)$ termasuk ke dalam kriteria rendah. Sebagian besar contoh menyebutkan tempat membeli buku bajakan adalah kios sekitar kampus. Alasan yang paling banyak dipilih konsumen $(78,0 \%)$ dalam membeli buku bajakan adalah buku bajakan memiliki harga yang murah. Contoh yang menyatakan akan tetap membeli buku bajakan walaupun contoh mengetahui bahwa hal tersebut dilarang oleh negara dan agama sebesar $90,7 \%$. Sebagian besar contoh $(77,3 \%)$ membeli buku bajakan berupa buku penunjang kuliah (textbook).

Tabel 6. Sebaran contoh berdasarkan perilaku membeli buku bajakan

\begin{tabular}{lrr}
\hline \multirow{2}{*}{ Keterangan } & \multicolumn{2}{c}{ Jumlah } \\
\cline { 2 - 3 } & $\mathbf{n}$ & \multicolumn{1}{c}{$\%$} \\
\hline Membeli buku bajakan dalam 1 tahun terakhir & \\
Sedikit (1-5) & 128 & 85,3 \\
Sedang (6-10) & 17 & 11,3 \\
Banyak (>11) & 5 & 3,4 \\
\hline Total & 150 & 100,0 \\
\hline Alokasi uang untuk membeli buku bajakan & \\
Tidak Menganggarkan & 32 & 21,3 \\
Rendah (<Rp 50.000,00) & 71 & 47,3 \\
Sedang (Rp 50.000,00-Rp & 33 & 22,0 \\
100.000,00) & & \\
Tinggi (>Rp 100.000,00) & 14 & 9,3 \\
\hline Total & 150 & 100,0 \\
\hline Tempat membeli buku bajakan & & \\
Kios di sekitar kampus & 118 & 78,7 \\
Kios di stasiun kereta & 19 & 12,7 \\
Kwitang & 20 & 13,3 \\
Lain-lain & 19 & 12,7 \\
\hline Alasan membeli buku bajakan & \multicolumn{2}{c}{} \\
Harga relatif murah & 117 & 78,0 \\
Cetakan bagus & 8 & 5,3 \\
Mudah didapat & 69 & 46,0 \\
Buku asli yang langka & 47 & 31,3 \\
Lain-lain & 20 & 13,3 \\
\hline
\end{tabular}




\section{Faktor-Faktor yang Mempengaruhi Sikap terhadap Buku Bajakan}

Nilai koefisien determinasi yang telah disesuaikan pada model yang telah disusun sebesar 0,144. Hal ini berarti sebanyak $14,4 \%$ variabel dependen persepsi dijelaskan oleh variabel independennya, dan sisanya $(85,6 \%)$ dijelaskan oleh variabel lain diluar variabel yang diteliti.

Usia $(0,023)$ berpengaruh nyata dengan nilai signifikan $\alpha<0,05$. Variabel independen yang berpengaruh secara signifikan pada $\alpha<0,01$ adalah alokasi uang $(0,007)$, pengetahuan $(0,002)$, dan control belief $(0,000)$. Perhitungan koefisien regresi linear untuk mengetahui faktor yang berpengaruh terhadap persepsi yang dihasilkan dalam penelitian ini adalah:

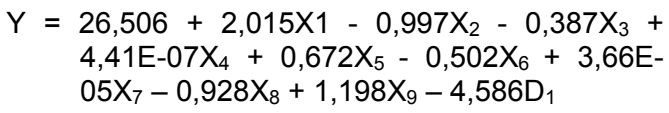

Keterangan:

$\mathrm{Y}=$ sikap terhadap buku bajakan

$\mathrm{a}=$ unstandardrized coefficient $\beta$

$\mathrm{X}_{1}=$ Usia (tahun)

$\mathrm{X}_{2}=$ Semester

$\mathrm{X}_{3}=$ Besar keluarga (org)

$\mathrm{X}_{4}=$ Pendapatan orangtua $(\mathrm{Rp})$

$\mathrm{X}_{5}=$ Frekuensi membaca

$\mathrm{X}_{6}=$ Frekuensi membeli buku

$\mathrm{X}_{7}=$ Alokasi uang membeli buku $(\mathrm{Rp})$

$\mathrm{X}_{8}=$ Jumlah sumber informasi

$\mathrm{X}_{9}=$ Pengetahuan

$\mathrm{D}_{1}=$ Control belief $(0=$ tidak, $1=\mathrm{ya})$

\section{Faktor-Faktor yang Mempengaruhi Perilaku Membeli Buku Bajakan}

Hasil menunjukkan $R^{2}(0,634)$ dari regresi logistik sebesar $63,4 \%$. Hal ini menunjukkan $3,4 \%$ variabel yang diinput mempengaruhi perilaku membeli buku bajakan. Sisanya dipengaruhi dari variabel diluar penelitian sebesar $36,6 \%$. Hasil penelitian menunjukkan bahwa sikap berhubungan negatif terhadap perilaku pembelian buku bajakan. Jika seseorang memiliki sikap positif terhadap perilaku pembelian buku bajakan adalah perbuatan yang salah, maka peluang untuk membeli buku bajakan tersebut akan menurun. Sikap adalah gambaran perasaan dari seorang konsumen, dan perasaan tersebut akan direfleksikan oleh perilakunya. Terlihat bahwa terdapat inkonsistensi antara sikap dan perilaku, yakni sikap contoh yang cenderung netral. Hal ini menegaskan bahwa faktor situasi akan menyebabkan inkonsistensi sikap. Seseorang yang menyatakan bahwa membeli buku bajakan adalah perbuatan yang salah, namun ia tetap membeli buku bajakan tersebut. Faktor daya beli atau kemudahan untuk memperoleh menyebabkan tidak konsistennya antara sikap dan perilaku.

Faktor yang mempengaruhi perilaku membeli buku bajakan yang dianalisis dengan menggunakan persamaan regresi logistik dapat dirumuskan dalam bentuk persamaan regresi sebagai berikut:

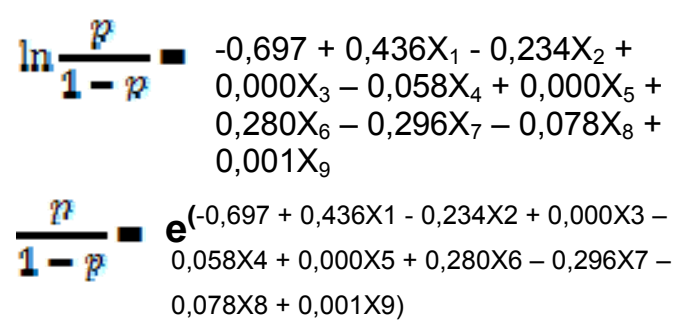

Keterangan:

$\mathrm{Y}=$ Peluang perilaku membeli buku bajakan ( $0=$ tidak membeli, $1=$ membeli)

$\mathrm{a}=$ unstandardrized coefficient $\beta$

$\mathrm{X}_{1}=$ Usia

$\mathrm{X}_{2}=\mathrm{IPK}$

$\mathrm{X}_{3}=$ Uang saku $(\mathrm{Rp})$

$\mathrm{X}_{4}=$ Besar keluarga (org)

$\mathrm{X}_{5}=$ Pendapatan orangtua $(\mathrm{Rp})$

$X_{6}=$ Jumlah sumber informasi

$\mathrm{X}_{7}=$ Pengetahuan

$\mathrm{X}_{8}=$ Sikap

$\mathrm{X}_{9}=$ Alokasi uang membeli buku $(\mathrm{Rp})$

\section{KESIMPULAN DAN SARAN}

\section{Kesimpulan}

Sebagian besar contoh membeli buku bajakan dalam satu tahun terakhir. Hampir seluruh contoh menyebutkan telah membeli buku bajakan antara satu hingga lima buku. Hampir sebagian contoh memiliki alokasi uang membeli buku bajakan kriteria rendah. Sebagian besar contoh menyatakan bahwa mereka membeli buku bajakan di daerah sekitar kampus. Teman adalah salah satu sumber informasi mengenai buku bajakan yang terbesar. Hampir dari separuh contoh memiliki pengetahuan dengan kriteria sedang.

Hasil penelitian ini menunjukkan bahwa terdapat inkonsistensi antara sikap dan perilaku, yakni sikap contoh yang cenderung netral. Sehingga faktor situasi akan menyebabkan inkonsistensi sikap. Seseorang yang menyatakan bahwa membeli buku bajakan adalah perbuatan yang salah, 
namun ia tetap membeli buku bajakan tersebut. Faktor daya beli atau kemudahan untuk memperoleh menyebabkan tidak konsistennya antara sikap dan perilaku. Faktor yang mempengaruhi sikap terhadap buku bajakan adalah usia, jumlah sumber informasi, pengetahuan, dan control believe. Faktor yang mempengaruhi perilaku membeli buku bajakan adalah sikap.

\section{Saran}

Mahasiswa sebagai seorang yang berintelektual sebaiknya membiasakan diri membaca buku tidak sebatas mengisi waktu luang, melainkan kebutuhan untuk menambah pengetahuan. Disamping itu, untuk mengurangi perilaku mahasiswa dalm membeli buku bajakan hendaknya IPB sebagai lembaga pendidikan agar dapat menambah koleksi buku perpustakaan untuk membantu mahasiswa memenuhi kebutuhan akan buku penunjang kuliah.

Pihak penerbit buku agar memperbanyak buku dengan penentuan harga yang mudah dijangkau oleh konsumen dari berbagai segmentasi pasar dan dapat melihat peluang besar bahwa Perguruan Tinggi merupakan pasar yang besar untuk penjualan buku. Pemerintah meningkatkan kebijakan subsidi kebutuhan buku bagi komunitas pendidikan, khususnya mahasiswa, karena dana APBN untuk pendidikan besar $(20 \%)$.

\footnotetext{
* Korespondensi:

Telp : +62-2518628303

Email : istiqlaliyah@yahoo.com
}

\section{DAFTAR PUSTAKA}

Akbar I. 2008. Analisis Faktor yang Berhubungan dengan Perilaku Membaca dan Tingkat Kepuasan Remaja terhadap Penerbit Komik Jepang (Manga) [skripsi]. Fakultas Pertanian, Institut Pertanian Bogor.

Anonim. 2008. Omzet Penjualan Buku Bajakan Diperkirakan 10 Persen. [terhubung berkala]. http://www.kompas.com/kompascetak/0 210/28/JATIM/omze50.htm [16 Januari 2009].

Astiwi H. 2007. Pola Membaca Remaja dan Pengaruhnya terhadap Perilaku Membaca (Kasus Siswa SMUN 2 Bogor, Jawa Barat) [skripsi]. Fakultas Pertanian, Institut Pertanian Bogor.

Engel JF, Blackwell RD, Miniard PW. 1994. Perilaku Konsumen Jilid 1. Jakarta: Binarupa Aksara.

Hurlock EB. 1980. Psikologi Perkembangan Suatu Pendekatan Sepanjang Rentang Kehidupan. Jakarta: Penerbit Erlangga.

Schiffman LG, Kanuk LL. 1994. Consumer Behaviour. Englewoods Cliffs: PrenticeHall.

Sumarwan U. 2002. Perilaku Konsumen Teori dan Penerapannya dalam Pemasaran. Jakarta: Ghalia Indonesia.

Umar H. 2003. Metode Riset Perilaku Konsumen Jasa. Jakarta: Ghalia Indonesia. 